\title{
Production of medium-chain-length polyhydroxyalkanoate by Pseudomonas oleovorans grown in sugary cassava extract supplemented with andiroba oil
}

\author{
Diego AIRES DA SILVA ${ }^{1}$ Regina Vasconcellos ANTONIO², José Márcio ROSSI ${ }^{3}$, Rosinelson da Silva PENA ${ }^{4 *}$
}

\begin{abstract}
Pseudomonas oleovorans were grown on sugary cassava extracts supplemented with andiroba oil for the synthesis of a mediumchain-length polyhydroxyalkanoate $\left(\mathrm{PHA}_{\mathrm{MCL}}\right)$. The concentration of total sugars in the extract was approximately: $40 \mathrm{~g} / \mathrm{L}$ in culture $1,15 \mathrm{~g} / \mathrm{L}$ in cultures 2 and 3 , and $10 \mathrm{~g} / \mathrm{L}$ in culture 4 . Supplementation with $1 \%$ andiroba oil and $0.2 \mathrm{~g} / \mathrm{L}$ of $\left(\mathrm{NH}_{4}\right)_{2} \mathrm{HPO}_{4}$ was performed 6.5 hours after growth in culture 3, and supplementation with the same amount of andiroba oil and $2.4 \mathrm{~g} / \mathrm{L}$ of $\left(\mathrm{NH}_{4}\right)_{2} \mathrm{HPO}_{4}$ was performed at the beginning of growth in culture 4 . The synthesis resulted mainly in 3-hydroxy-decanoate and 3-hydroxy-dodecanoate units; 3-hydroxy-butyrate, 3-hydroxy-hexanoate; and 3-hydroxy-octanoate monomers were also produced but in smaller proportions. P. oleovorans significantly accumulated $\mathrm{PHA}_{\mathrm{MCL}}$ in the deceleration phase of growth with an oxygen limitation but with sufficient nitrogen concentration to maintain cell growth. The sugary cassava extract supplemented with andiroba oil proved to be a potential substrate for PHA $_{\mathrm{MCL}}$ production.
\end{abstract}

Keywords: Manihot esculenta; Carapa guianensis; biopolymers; airlift.

\section{Introduction}

Plastics are found everywhere in society, and problems with plastic residues include extensive accumulations in landfills and in terrestrial and aquatic ecosystems, which affect wildlife and human health (Lithner et al., 2011; Bugnicourt et al., 2014). These problems have encouraged researchers to study biodegradable plastic materials that could replace petrochemical polymers; polyhydroxyalkanoates (PHAs) have emerged as a promising alternative (Steinbüchel, 2010; Saharan et al., 2014; Urtuvia et al., 2014).

PHAs are a class of natural polyesters that can be accumulated by various microorganisms when there is an excess of available carbon and a limited supply of at least one nutrient essential to bacterial cell growth (Borges et al., 2004; Saharan et al., 2014; Urtuvia et al., 2014). Bacteria of the genus Pseudomonas, which belongs to ribosomal RNA homology group I, are able to synthesize PHA using a variety of carbon sources, including glucose, fructose and sucrose (Diniz et al., 2004; Santhanam \& Sasidharan, 2010; Davis et al., 2013), n-octane and octanoate (Smet et al., 1983; Durner et al., 2000), and fatty acids (Du \& Yu, 2002; Allen et al., 2010), among others.

P. oleovorans shows the specific ability to synthesize mediumchain-length PHAs (monomers with 6 to 16 carbon atoms in the main chain) from fatty acids ( $\beta$-oxidation) (Fiedler et al., 2002), and sugars (de novo biosynthesis) (Huisman et al., 1989). That ability has encouraged the use of different combinations of carbohydrates and lipids to produce biopolymers with particular properties and function; such combinations include the glucose/lipid mixture (Ashby et al., 2001), hydrolyzed corn oil (Shang et al., 2008), cassava wastewater (Costa et al., 2009), whey and starch sources (Steinbüchel, 2010), and palm oil (Sudesh et al., 2011).

Cassava (Manihot esculenta Crantz) has previously been identified as an important carbon source for biotechnological processes (Pandey et al., 2000). Ramadas et al. (2009) and Aremu et al. (2010) produced PHAs from enzymatically and thermally hydrolyzed cassava starch. Using cassava wastewater, Nitschke \& Pastore (2006) produced biosurfactants, and Costa et al. (2009) produced PHAs and rhamnolipids.

Brazil is the place of origin of cassava having a substantial diversity with a large collection of different varieties (Olsen, 2004). Sugary cassava, or mandiocaba, is a variety of cassava with a high content of free sugars, such as glucose, fructose, and sucrose. Unlike most varieties, sugary cassava is not predominantly starch (Carvalho et al., 2004). Vieira et al. (2011) found genetic differences between sugary and non-sugary cassava varieties in terms of carbohydrate reserves. According to Carvalho et al. (2004), the difference in the distribution patterns of starch and free sugars can be attributed to the hydrolysis of starch either by the phosphorylytic degradation mechanism or by the cleavage of starch by a series of starch hydrolytic enzymes, such as that occurring during seed germination in cereals, or by both.

In biotechnological processes used in PHA production, such as submerged fermentation, sugary cassava stands out as an attractive carbon source because it can be used to prepare 
an extract with a high concentration of free monosaccharides (glucose and fructose) (Vieira et al., 2011). Thus, the starch hydrolysis step may be omitted in the production of fermentable sugars that are able to sustain bacterial growth and biopolymer production, reducing production costs.

Since the cost of PHA production is much higher than that of non-biodegradable synthetic plastics, alternative production methods have been explored, including the maximization of carbon conversion and the productivity of bioprocesses using less expensive carbon sources (Steinbüchel, 2010; Bera et al., 2015; Berezina et al., 2014). Accordingly, the present study aimed to produce $\mathrm{PHA}_{\mathrm{MCL}}$ by $P$. oleovorans isolate using sugary cassava extract with and without fatty acid supplementation (andiroba oil).

\section{Material and methods}

\subsection{Microorganism, sugary cassava extract, and andiroba oil}

The bacteria Pseudomonas oleovorans, ATCC29347 isolate, was provided by the Department of Biochemistry at the Center of Biological Sciences, Federal University of Santa Catarina, Brazil. The microorganism was maintained at $25^{\circ} \mathrm{C}$ on a solid culture medium containing (per liter): $10.0 \mathrm{~g}$ of tryptone, $5.0 \mathrm{~g}$ of yeast extract, $5.0 \mathrm{~g}$ of sodium chloride, and $15.0 \mathrm{~g}$ of Agar.

A producer in the state of Pará, Brazil (Latitude $01^{\circ} 27^{\prime} 21^{\prime \prime}$ $\mathrm{S}$ and Longitude $48^{\circ} 30^{\prime} 16^{\prime \prime} \mathrm{W}$ ) provided the sugary cassava roots. To prepare the sugary cassava extract, the roots were washed, peeled, and ground using an industrial blender (POLI LS-4, Siemsen, Brazil). The material was filtered through 60 and 200 mesh sieve; the eluted fraction was allowed to stand and the starch was decanted. The supernatant - the sugary cassava extract - was separated and stored at $-18{ }^{\circ} \mathrm{C}$ until use.

The andiroba oil was obtained through mechanical extraction by mechanical pressing of the andiroba kernels (Carapa guianensis Aubl.) using a continuous screw press (MPE-40 R, Ecirtec, Brazil). The extract was pumped through a filter press (FPE-25/10 AC, Ecirtec, Brazil) and refrigerated $\left(5^{\circ} \mathrm{C}\right)$ in the dark until use.

\subsection{Bioreactor}

A stainless steel airlift bioreactor with external circulation and a working capacity of 5 liters was used. The reactor was equipped with control systems for $\mathrm{pH}$, temperature, and dissolved oxygen. Sterilization of the air filtration membrane (PTFE, $0.2 \mathrm{~mm}$, Millipore) and the acid and base solutions was performed at $121{ }^{\circ} \mathrm{C}$ for $20 \mathrm{~min}$. The bioreactor was sterilized with direct steam.

\subsection{Characterization of the sugary cassava extract and the andiroba oil}

Glucose, fructose, and sucrose concentrations in the sugary cassava extract were assessed in a reaction medium containing ATP, NAD+ and glucose-6-phosphate dehydrogenase (G6PDH), to which hexokinase, phosphoglucoisomerase (PGI), and invertase (or $\beta$-fructosidase) were sequentially added to assess the sugars. In this process, hexokinase mediates phosphorylation of glucose to glucose-6-phosphate (G6P) using ATP. Next, G6P is oxidized by G6PDH to gluconate-6-phosphate using $\mathrm{NAD}+$ as the oxidant coenzyme. PGI converts fructose-6phosphate (F6P) into G6P, and $\beta$-fructosidase converts sucrose into glucose + fructose. NADH production was detected by the change of absorbance intensity at $340 \mathrm{~nm}$ measured using a spectrophotometer adapted to an Elisa plate reader (Praxedes et al., 2006). Moisture, ash, and protein (6.25 nitrogento-protein conversion factor) of the sugary cassava extract were also assessed using official methods (Association of Official Anaytical, 1997). The primary fatty acids in the andiroba oil were quantified by gas chromatography in accordance with Darnet et al. (2011).

\subsection{Inoculum and culture medium preparation}

The inoculum was produced from a pre-inoculum that was prepared inoculating a single colony and transferred to an Erlenmeyer flask containing $100 \mathrm{~mL}$ of sterile sugary cassava extract $\left(120^{\circ} \mathrm{C} / 20 \mathrm{~min}\right)$. The culture was incubated for 18 hours at $30^{\circ} \mathrm{C}$ under orbital shaking of $0.55 \mathrm{~g}$. Following incubation, the pre-inoculum was transferred to another flask with $400 \mathrm{~mL}$ of extract, which was kept under aeration by injection of sterile air (filtered in a $0.2 \mathrm{~mm}$ PTFE Millipore membrane) for 24 hours at $30^{\circ} \mathrm{C}$.

As for the cultures in the bioreactor, $1 \mathrm{M} \mathrm{HCl}$ was initially added to the extract until $\mathrm{pH} 3.8$; this step was performed for precipitation of carotenoids that give the extract a yellow color and which were later removed by filtration (Watman No. 12 filter). Next, the extract was supplemented with the following nutrients (per liter): $5.8 \mathrm{~g}$ of $\mathrm{K}_{2} \mathrm{HPO}_{4}, 3.7 \mathrm{~g}$ of $\mathrm{KH}_{2} \mathrm{PO}_{4}$, $0.25 \mathrm{~g}$ of $\mathrm{MgSO}_{4} .7 \mathrm{H}_{2} \mathrm{O}$, and $1.6 \mathrm{~g}$ of $\left(\mathrm{NH}_{4}\right)_{2} \mathrm{HPO}_{4}$. Following supplementation, $1 \mathrm{M} \mathrm{NaOH}$ was added to adjust the $\mathrm{pH}$ to 7.0. Andiroba oil supplementation was performed during cultivation in the bioreactor. The culture media were preheated to $100{ }^{\circ} \mathrm{C}$ for 60 minutes before inoculation and later cooled to $30^{\circ} \mathrm{C}$.

\subsection{Cultures}

Four cultures (Pseudomonas oleovorans+culture medium) were grown in the bioreactor under the following conditions: culture 1 - sugary cassava extract with approximately $40 \mathrm{~g} / \mathrm{L}$ of total sugars; culture 2 - sugary cassava extract diluted to approximately $15 \mathrm{~g} / \mathrm{L}$ of total sugars; culture 3 - same diluted extract as that of culture 2 but supplemented with $1 \%(\mathrm{v} / \mathrm{v})$ andiroba oil and $0.2 \mathrm{~g} / \mathrm{L}$ of $\left(\mathrm{NH}_{4}\right)_{2} \mathrm{HPO}_{4}$ after 6.5 hours of growth; and culture 4 - sugary cassava extract diluted to approximately $10 \mathrm{~g} / \mathrm{L}$ of total sugars, supplemented with $1 \%$ (v/v) andiroba oil and $2.4 \mathrm{~g} / \mathrm{L}$ of $\left(\mathrm{NH}_{4}\right)_{2} \mathrm{HPO}_{4}$ at the onset of growth.

In each culture, $4.5 \mathrm{~L}$ of culture medium were used, to which $1 \mathrm{~mL} / \mathrm{L}$ of polypropylene glycol antifoam was added. The medium was transferred to the bioreactor under aseptic conditions following heat treatment $\left(100{ }^{\circ} \mathrm{C} / 1\right.$ hour $)$ and cooling $\left(30^{\circ} \mathrm{C}\right)$. Aeration and oxygen saturation (>20 min) were initiated after the temperature of the medium stabilized at $30^{\circ} \mathrm{C}$. Following this step, $500 \mathrm{~mL}$ of inoculum were aseptically 
introduced into the bioreactor, which resulted in an initial biomass concentration of $0.5 \mathrm{~g} / \mathrm{L}$. The control system was programmed to maintain the dissolved oxygen concentration above the critical level, pre-set at $13 \%$, which required an airflow rate from 0.25 to $1.3 \mathrm{vvm}$ (volume of air per volume of reaction per minute). The air pressure at the top of the bioreactor was maintained at $50.7 \mathrm{kPa}$ during the periods of higher oxygen demand.

\subsection{Analytical assessments during growth}

To monitor the cultures, $15 \mathrm{~mL}$ aliquots were taken consecutively, which were initially centrifuged for cell separation at $8000 \mathrm{~g}$ for 5 minutes. Cell concentration was determined by gravimetry through oven drying $\left(75^{\circ} \mathrm{C}\right)$ to a constant weight. Residual glucose and nitrogen were quantified in the supernatant by an enzymatic-colorimetric method using a commercial kit (Gold Analisa, Brazil) (Trinder, 1969). The dry cell mass was subjected to acid methanolysis, as described by Braunegg et al. (1978) and with the modifications proposed by Brandl et al. (1988), for PHA quantification. A gas chromatograph (GC-2014, Shimadzu, Columbia) with a flame ionization detector (FID) was used in the identification and quantification of PHAs. A fused silica capillary column (Supelcowax 10, $0.32 \mathrm{~mm}$ x $30 \mathrm{~m}$ ) was utilized. The carrier gas was hydrogen at $20 \mathrm{~mL} / \mathrm{min}$, and the temperatures at injection, detection, and at the column were $250{ }^{\circ} \mathrm{C}, 280^{\circ} \mathrm{C}$ and $50{ }^{\circ} \mathrm{C}$, respectively. A standard curve was constructed with the following standards: $\mathrm{P}(3 \mathrm{HO}-c o-3 \mathrm{HHx})$, (92.71\% 3HO and 7.29\% 3HHx), $\mathrm{P}(3 \mathrm{HD}-c o-3 \mathrm{HDd}-c o-3 \mathrm{HO})$, and $(50.59 \% 3 \mathrm{HD}, 15.07 \% 3 \mathrm{HDd}, 34.33 \% 3 \mathrm{HOx})$.

\subsection{Mathematical treatment}

Cell growth during the exponential phase is described by Equation 1; the integrated form of which (Equation 2) was used to determine the maximum specific growth rate $\left(\mathrm{m}_{\max }\right)$, which is the slope of the $\ln \mathrm{X}$ versus $\mathrm{t}$ correlation. Conversely, the biomass yield coefficient $\left(\mathrm{Y}_{\mathrm{X} / \mathrm{S}}\right)$ of a batch culture at a constant volume is defined by Equation 3; the slope of its integrated form (Equation 4) therefore enabled the determination of $\mathrm{Y}_{\mathrm{X} / \mathrm{s}}$. Linear

(a)

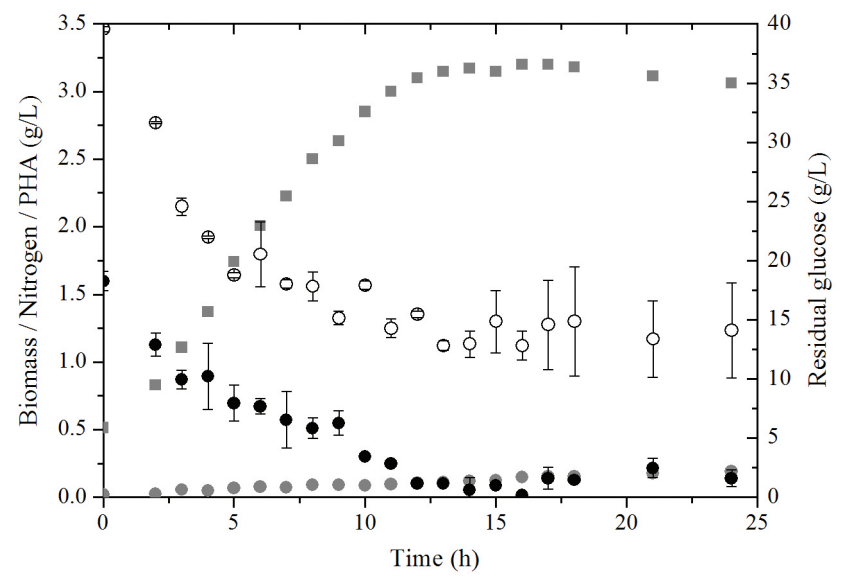

regression analysis was conducted using Microsoft Office Excel 2007 software.

$\mathrm{dX} / \mathrm{dt}=\mathrm{m}_{\max } \mathrm{X}$

$\ln X=\ln X_{o}+m_{\max } t$

$\mathrm{Y}_{\mathrm{X} / \mathrm{S}}=-\left(\mathrm{d}_{\mathrm{X}} / \mathrm{d}_{\mathrm{S}}\right)$

$\mathrm{Y}_{\mathrm{X} / \mathrm{S}}=\left(\mathrm{X}-\mathrm{X}_{\mathrm{o}}\right) /\left(\mathrm{S}_{\mathrm{o}}-\mathrm{S}\right)$

where $\mathrm{X}=$ biomass concentration $(\mathrm{g} / \mathrm{L}), \mathrm{X}_{\mathrm{o}}=$ initial biomass concentration $(\mathrm{g} / \mathrm{L}), \mathrm{S}=$ substrate concentration $(\mathrm{g} / \mathrm{L}) ; \mathrm{S}_{\mathrm{o}}=$ initial substrate concentration $(\mathrm{g} / \mathrm{L}), \mu_{\max }=$ maximum specific growth rate $\left(\mathrm{h}^{-1}\right), \mathrm{t}=$ time $(\mathrm{h})$, and $\mathrm{Y}_{\mathrm{x} / \mathrm{s}}=$ biomass yield coefficient $\left(\mathrm{g}_{\mathrm{x}} / \mathrm{g}_{\mathrm{S}}\right)$.

\section{Results and discussion}

\subsection{Proximate composition of sugary cassava extract and andiroba oil}

The sugary cassava extract, which represented $61.40 \%$ of the root weight, had $94.15 \%( \pm 0.11)$ moisture, $0.12 \%( \pm 0.08)$ ashes, $0.19 \%( \pm 0.03)$ proteins, $1.29 \%( \pm 0.09)$ sucrose, $2.26 \%( \pm 0.04)$ glucose, and $1.65 \%( \pm 0.06)$ fructose. The high concentrations of free sugars demonstrated that sugary cassava extract is an excellent source of fermentable sugars.

According to its fatty acid profile, andiroba oil had $0.21 \%$ myristic acid (C14:0), 28.29\% palmitic acid (C16:0), 1.07\% palmitoleic acid (C16:1), 8.46\% stearic acid (C18:0), 50.70\% oleic acid (C18:1), 9.88\% linoleic acid (C18:2), and $1.39 \%$ linolenic acid (C18:3). Abreu et al. (2004) found a similar profile for andiroba oil.

\subsection{Polyhydroxyalkanoate production in Airlift bioreactor}

Figure 1 shows the results obtained for culture 1, in which sugary cassava extract was the only carbon source. Figure 1a shows that there was cell growth for approximately up to 12 hours under those conditions; at that time, practically all

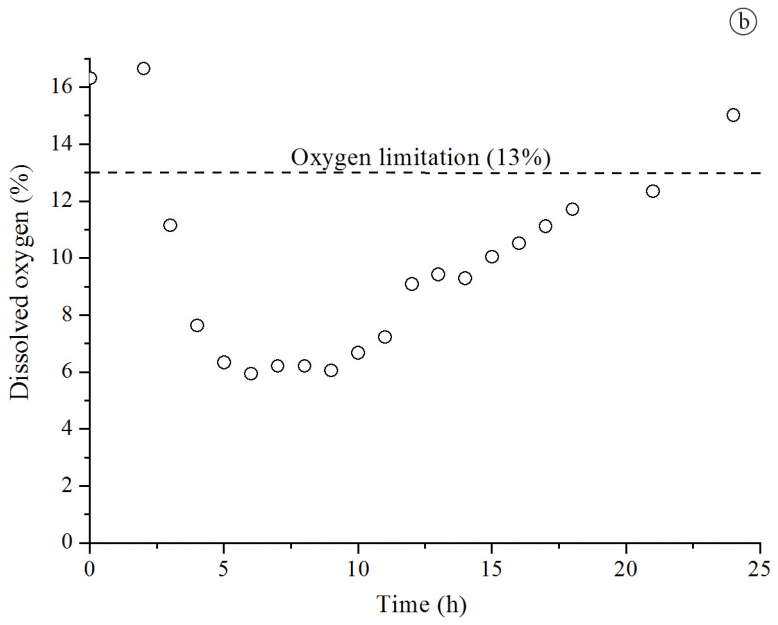

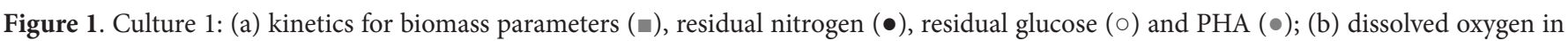
the culture medium. 
nitrogen was consumed, and a stationary phase of bacterial growth was initiated. From that point onwards, there was no noticeable variation in substrate consumption, and the medium retained approximately $12 \mathrm{~g} / \mathrm{L}$ of residual glucose at the end of the process, which indicated that the P. oleovorans did not consume the entire substrate. The culture produced a biomass yield coefficient $\left(\mathrm{Y}_{\mathrm{X} / \mathrm{S}}\right)$ of $0.19 \mathrm{~g}_{\mathrm{X}} / \mathrm{g}_{\mathrm{S}}$, a maximum specific growth rate $\left(\mu_{\max }\right)$ of $0.25 \mathrm{~h}^{-1}$, the exponential growth phase lasted up to five hours, and the maximum biomass concentration was $3.20 \mathrm{~g} / \mathrm{L}$ in 16 hours of cultivation.

The critical oxygen level during culture growth was $13 \%$ of saturation level; below this level, oxygen is limited. Thus, dissolved oxygen was limited in the medium during virtually all growth (Figure 1b). The bioreactor therefore had to be pressurized with $25 \mathrm{kPa}$ even before the first hour of growth to prevent the concentration of dissolved oxygen from reaching values close to zero. The pressure was adjusted to $100 \mathrm{kPa}$ after the third hour of growth and maintained at that condition until the end of the process. Despite the high oxygen demand observed, oxygen may have been limited because of the osmotic stress of the cell resulting from the high concentration of substrate; this hypothesis must not be overlooked because the exponential phase was not well-characterized, including the times that oxygen was above the critical concentration. Under the conditions of culture 1 , the PHA production reached a maximum of $6.26 \%$ after 24 hours of growth, and the product yield coefficient $\left(\mathrm{Y}_{\mathrm{P} / \mathrm{S}}\right)$ was $0.0034 \mathrm{~g}_{\mathrm{P}} / \mathrm{g}_{\mathrm{S}}$.

The performance of culture 1 indicated the need to reduce the carbon/oxygen ratio in the culture medium to avoid or minimize oxygen limitation. Therefore, in culture 2, the concentration of total sugars in the sugary cassava extract was reduced to approximately $15 \mathrm{~g} / \mathrm{L}$. Under this condition, cell growth time was reduced to eight hours (Figure 2a), which was four hours less than that of culture 1; there was an increase in the maximum specific growth rate $\left(\mu_{\max }=0.36 \mathrm{~h}^{-1}\right)$, and the exponential growth phase was also extended to up to five hours of growth, which coincided with the point at which the oxygen concentration became critical (Figure 2b). The maximum biomass concentration was $3.20 \mathrm{~g} / \mathrm{L}$ in 16 hours of growth under the same conditions as those of culture 1; however, the biomass yield coefficient $\left(\mathrm{Y}_{\mathrm{X} / \mathrm{S}}=0.26 \mathrm{~g}_{\mathrm{X}} / \mathrm{g}_{\mathrm{S}}\right)$ and the product yield coefficient $\left(\mathrm{Y}_{\mathrm{P} / \mathrm{S}}=0.0084 \mathrm{~g}_{\mathrm{P}} / \mathrm{g}_{\mathrm{S}}\right)$ were higher in culture 2 . Substrate dilution improved bacterial growth conditions, but the maximum PHA concentration (6.50\%) had the same order of magnitude as that of culture 1 in 16 hours of growth. The consumption of the previously synthesized PHA was observed thereafter, which indicated that the use of $P$. oleovorans requires special attention in the control of high stress. Huijberts et al. (1992) identified intracellular enzymes in P. oleovorans named PHA depolymerases, and Knoll et al. (2009) reported that this family of enzymes hydrolyzes intracellular PHA granules under extreme environmental conditions, such as nutrient and oxygen limitation.

Based on the finding that the point of nitrogen limitation coincided with the end of the cellular growth phase in culture 2 , although at low levels of carbon ( $<4 \mathrm{~g} / \mathrm{L}$ of glucose), a new cultivation condition was defined to enable the maintenance of that microbial stress point for a longer period of time and to increase the accumulation of PHA in cells. Thus, the concentration of total sugars in the sugary cassava extract was maintained at approximately $15 \mathrm{~g} / \mathrm{L}$ in culture 3 , but the culture medium was supplemented with $0.2 \mathrm{~g} / \mathrm{L}$ of $\left(\mathrm{NH}_{4}\right)_{2} \mathrm{HPO}_{4}$ as a source of nitrogen and with $1 \%(\mathrm{v} / \mathrm{v})$ andiroba oil as a lipid co-substrate. Supplementations were performed after 6.5 hours of growth because nitrogen limitation occurred at that time in culture 2 (Figure 2a), and the culture, which had not yet reached stationary phase that would minimize the effect of supplementation with andiroba oil on cell growth and enable the production of lipases that are responsible for the hydrolysis and release of fatty acids.

Cell growth lasted up to ten hours in culture 3, and the exponential growth phase lasted up to 8 hours of cultivation, higher than the 5 hour-growth observed in cultures 1 and 2 . The maximum specific growth rate $\left(\mathrm{m}_{\max }=0.23 \mathrm{~h}^{-1}\right)$ and the biomass yield coefficient $\left(\mathrm{Y}_{\mathrm{X} / \mathrm{S}}=0.17 \mathrm{~g}_{\mathrm{X}} / \mathrm{g}_{\mathrm{S}}\right)$ of culture 3 were lower than those of culture 2, but the maximum biomass concentration

(a)
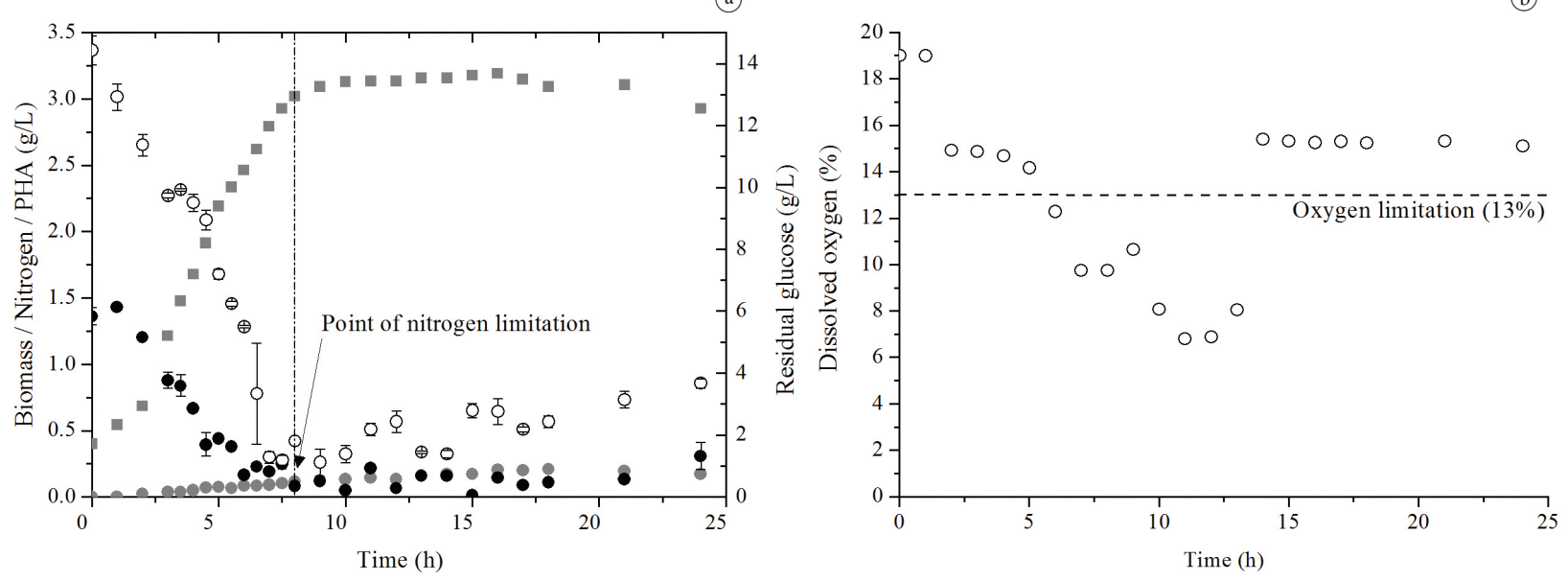

Figure 2. Culture 2: (a) kinetics for biomass parameters (₫), residual nitrogen $(\bullet)$, residual glucose (०) and PHA (•); (b) dissolved oxygen in the culture medium. 
$(\mathrm{X}=3.61 \mathrm{~g} / \mathrm{L})$ in 24 hours of cultivation and the product yield coefficient $\left(\mathrm{Y}_{\mathrm{P} / \mathrm{S}}=0.0340 \mathrm{~g}_{\mathrm{p}} / \mathrm{g}_{\mathrm{S}}\right)$ were higher. The concentration of dissolved oxygen in culture 3 reached the critical limit (Figure $3 \mathrm{~b}$ ) in less time than in culture 2 (Figure $2 \mathrm{~b}$ ), but that critical condition remained the same in both cultures for virtually the same period of time. PHA production in culture 3 reached a maximum of $15.96 \%$ in 24 hours of process, which is more than twice the production observed in cultures 1 and 2 and is attributable to the addition of andiroba oil.

According to Figure 3a, supplementation with $\left(\mathrm{NH}_{4}\right)_{2} \mathrm{HPO}_{4}$ in culture 3 kept the nitrogen concentration constant $(\approx 0.6 \mathrm{~g} / \mathrm{L})$ for approximately 2 hours thereafter; after this point, the nitrogen concentration decreased again until it reached the critical limit after approximately 15 hours of cultivation. There was a sudden increase in dissolved oxygen to a concentration above the critical (Figure 3b) at approximately 10 hours of cultivation, which indicates a deceleration of bacterial metabolism, as confirmed by the maintenance of $4 \mathrm{~g} / \mathrm{L}$ of residual glucose in the medium (Figure 3a), from the point of nitrogen limitation.

The performance observed under the conditions of culture 3 suggests that $P$. oleovorans significantly accumulated PHA in the deceleration phase of growth under oxygen limitation but with sufficient nitrogen to sustain growth under limiting conditions, which prevented cellular metabolic processes and polymer production processes from stopping. Smet et al. (1983) and Huisman et al. (1992) found similar results and observed an increase in biomass following nutrient limitation, which was related to PHA accumulation.

Culture 4 was formulated based on the results of culture 3 but with an increase in nitrogen concentration to $2.4 \mathrm{~g} / \mathrm{L}$ and a reduction in the concentration of sugars in sugary cassava extract to approximately $10 \mathrm{~g} / \mathrm{L}$ of glucose. Culture 4 was supplemented with nitrogen and andiroba oil at the onset of the cultivation; enzyme production was thus induced from the start of the process, increasing the availability of acil-CoA produced by $\beta$-oxidation of fatty acids (Du \& Yu 2002), which was immediately incorporated into the polymer when stress conditions favored PHA production.

The results of culture 4 are shown in Figure 4. Cell growth was linear in that culture (Figure $4 \mathrm{a}$ ), indicating limitation in the first hours of the process, which was confirmed by the maintenance of the oxygen concentration in the system

(a)
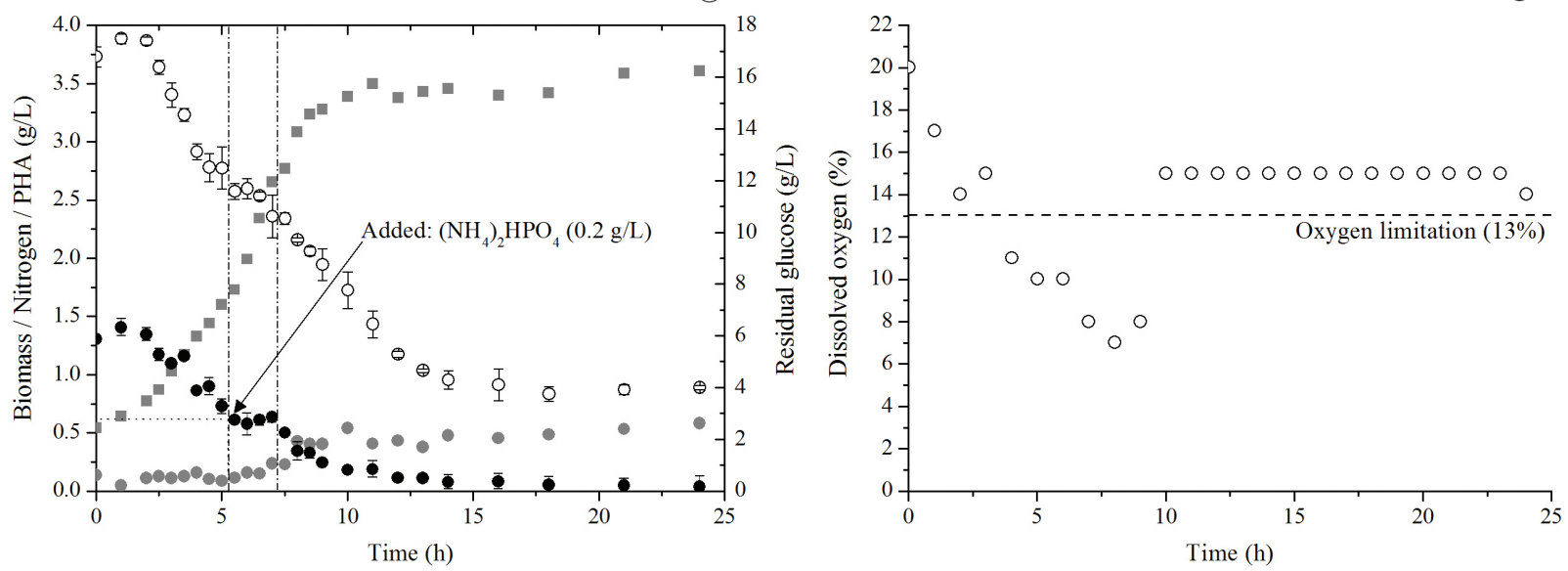

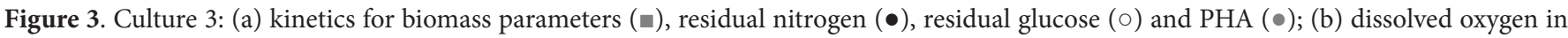
the culture medium.

(a)

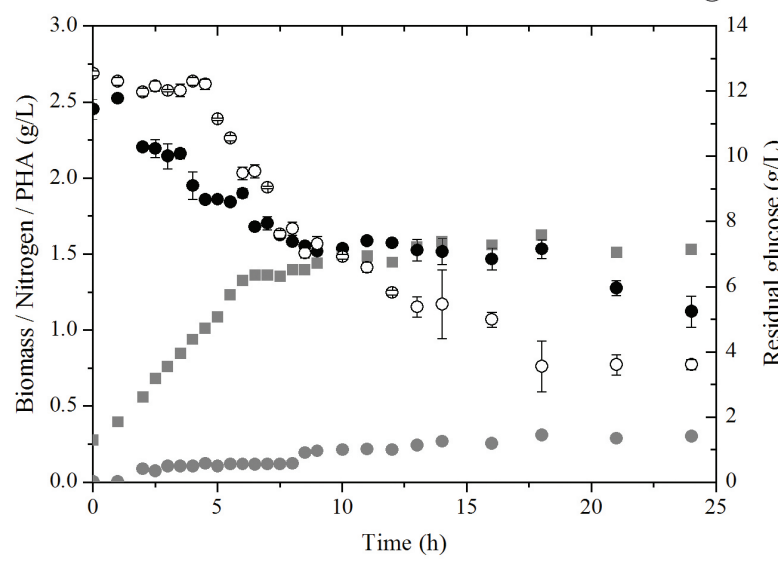

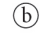

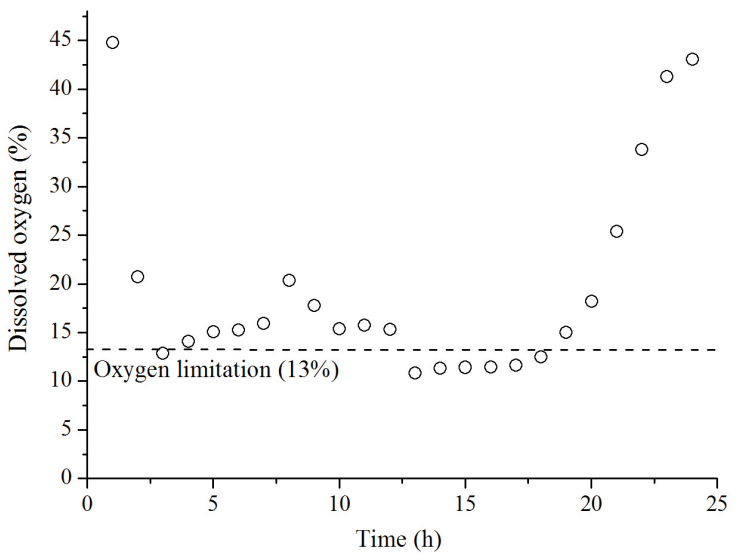

Figure 4. Culture 4: (a) kinetics for biomass parameters (₫), residual nitrogen $(\bullet)$, residual glucose (०) and PHA (•); (b) dissolved oxygen in the culture medium. 
near or above the critical concentration during the entire process (Figure $4 \mathrm{~b}$ ). Although biomass production in culture 4 was less than half of that observed in the remaining cultures $(1.54 \mathrm{~g} / \mathrm{L})$, this process conditions resulted in the highest PHA concentration $(18.41 \%)$. There was an increase of the maximum specific growth rate $\left(\mathrm{m}_{\max }=0.27 \mathrm{~h}^{-1}\right)$ and the biomass yield coefficient $\left(\mathrm{Y}_{\mathrm{X} / \mathrm{s}}=0.23 \mathrm{~g}_{\mathrm{X}} / \mathrm{g}_{\mathrm{S}}\right)$ in relation to culture 3, but the product yield coefficient $\left(\mathrm{Y}_{\mathrm{p} / \mathrm{S}}=0.0270 \mathrm{~g}_{\mathrm{p}} / \mathrm{g}_{\mathrm{S}}\right)$ decreased.

Table 1 shows the main products of the four cultures, and it can be seen that the copolymers predominantly produced were 3-hydroxy-decanoate (3HD) and 3-hydroxydodecanoate (3HDD). The monomers 3-hydroxybutyrate (3HB), 3-hydroxyhexanoate (3HHx), and 3-hydroxy-octanoate $(3 \mathrm{HO})$ were also incorporated. Co-polymers with short- and medium-chain-length monomeric units were produced mainly when the sugary cassava extract was supplemented with andiroba oil. In studies using other strains of Pseudomonas and mixtures of lipids and carbohydrates as carbon sources, Ashby et al. (2001) and Costa et al. (2009) did not detect production of these copolymers. On the other hand, Srivastava \& Tripathi (2013) observed production of PHAs with short- and medium-chain-length in a study using Alcaligenes sp. strains and fructose supplemented with palmitic, stearic, oleic, and linoleic fatty acids. This type of polymer can have highly specific applications because it has physical and chemical properties that are intermediate between crystalline polymers, such as polyhydroxybutyrate (PHB) and elastomers, namely mediumchain-length polyhydroxyalkanoate $\left(\mathrm{PHA}_{\mathrm{MCL}}\right)$.

There is a relevant aspect obtained in the present study (Table 2) that relates to stoichiometric results. In general, the biomass yield coefficient $\left(\mathrm{Y}_{\mathrm{x} / \mathrm{S}}\right)$ were low compared to the values found by Durner et al. (2000) (0.62 to $0.97 \mathrm{~g}_{\mathrm{x}} / \mathrm{g}_{\mathrm{s}}$ ), who studied poly[(R)-3-hydroxyalkanoates] accumulation in $P$. oleovorans using octanoate as a substrate. The performance observed here can be attributed to the metabolic flux that is related to PHA production with respect to the use of cellular energy or as a result of physical impediments by the intracellular granules formed preventing cell division, which contributed to low biomass production.

A study conducted by Escapa et al. (2012) on the distribution of energy involved in the metabolic flux of PHA accumulation in wild-type and genetically modified strains of Pseudomonas putida showed that there was an increase of acetyl CoA synthesis at low levels of nitrogen, which was detrimental to the PHA cycle. According to these authors, the excess of acetyl$\mathrm{CoA}$ favored the citric acid cycle, increasing respiration and $\mathrm{CO}_{2}$ production and thus hindering biomass production and dissipating energy. In that case, PHA synthesis in P. putida would be a method of channeling excess energy and thus maintaining the equilibrium and energy balance of bacterial metabolism.

The pre-assumptions shown may be used as the basis to explain the low biomass yield coefficient $\left(\mathrm{Y}_{\mathrm{x} / \mathrm{s}}\right)$ observed in the current study. However, there is a need for more specific studies examining the metabolism of PHA accumulation in P. oleovorans under these conditions. Nevertheless, the findings of the present study indicate that a process with separate cellular growth and
Table 1. Summary of PHA production by $P$. oleovorans from sugary cassava extract and andiroba oil in 24 hours.

\begin{tabular}{ccrccc}
\hline \multirow{2}{*}{ Experiment } & \multicolumn{5}{c}{ PHA $(\mathrm{mol} \%)^{*}$} \\
\cline { 2 - 6 } & \multicolumn{1}{c}{$3 \mathrm{HB}$} & 3HHx & \multicolumn{1}{c}{$3 \mathrm{HO}$} & 3HD & 3HDD \\
\hline Culture 1 & $\mathrm{ND}$ & 0.58 & 10.98 & 54.87 & 33.57 \\
Culture 2 & Trace & 0.25 & 6.77 & 44.56 & 32.63 \\
Culture 3 & 11.06 & 11.65 & 21.87 & 35.54 & 19.9 \\
Culture 4 & 12.24 & 5.42 & 21.88 & 40.25 & 20.21 \\
\hline
\end{tabular}

*Monomer composition of PHA: 3HB: 3-hydroxybutyrate; 3HHx: 3-hydroxyhexanoate; 3HO: 3-hydroxyoctanoate; 3HD: 3-hydroxydecanoate; 3HDD: 3-hydroxydodecanoate. $\mathrm{ND}$ - not detected.

Table 2. Kinetic and culture parameters of $P$. oleovorans grown in Airlift bioreactor.

\begin{tabular}{ccccccc}
\hline Experiment & $\mu_{\max }$ & $\mathrm{R}^{2}$ & $\mathrm{Y}_{\mathrm{X} / \mathrm{S}}$ & $\mathrm{R}^{2}$ & $\mathrm{Y}_{\mathrm{P} / \mathrm{S}}$ & $\mathrm{R}^{2}$ \\
\hline Culture 1 & 0.25 & 0.99 & 0.19 & 0.88 & 0.0034 & 0.90 \\
Culture 2 & 0.36 & 0.99 & 0.26 & 0.94 & 0.0084 & 0.92 \\
Culture 3 & 0.23 & 0.99 & 0.17 & 0.97 & 0.0340 & 0.80 \\
Culture 4 & 0.27 & 0.99 & 0.23 & 0.98 & 0.0270 & 0.90 \\
\hline
\end{tabular}

$\mathrm{m}_{\max }$, maximum specific growth rate $\left(\mathrm{h}^{-1}\right) ; \mathrm{t}$, time $(\mathrm{h}) ; \mathrm{Y}_{\mathrm{x} / \mathrm{s}}$, biomass yield coefficient $\left(\mathrm{g}_{\mathrm{X}} / \mathrm{g}_{\mathrm{S}}\right)$; $\mathrm{Y}_{\mathrm{P} / \mathrm{S}}$, product yield coefficient $\left(\mathrm{g}_{\mathrm{p}} / \mathrm{g}_{\mathrm{S}}\right) ; \mathrm{R}^{2}$, coefficient of determination.

biopolymer production phases would be an effective strategy to increase PHA production. In the growth phase, particular focus should be directed toward oxygen supply, ensuring that its concentration is maintained above the critical level and at a convenient carbon/nitrogen ratio. In the phase of biopolymer accumulation, supplementation with lipid co-substrate and the maintenance of limiting levels of oxygen are key conditions. The process can be studied in an airlift bioreactor, but it requires the application of other forms of operation, including a continuous cultivation phase to keep cell concentrations low and to avoid oxygen limitation and a batch phase in another reactor with oil supplementation and oxygen limitation. Providing conditions that limit cell growth by controlling oxygen is much more practical than using any other nutrient.

\section{Conclusions}

P. oleovorans accumulated PHA in sugary cassava extract supplemented with andiroba oil in the deceleration phase of growth and under oxygen-limiting conditions. This process is an attractive alternative to produce biopolymers because controlling dissolved oxygen in bioreactors is simpler than controlling other nutrients. However, conditions of high stress must be avoided because they favor the intracellular depolymerization of previously synthesized PHA. Co-polymers with short- and medium-chain-length monomeric units were produced, which may have highly specific applications. The two-stage process (biomass accumulation and PHA production separately) may be a useful strategy to optimize the production process of these biopolymers.

\section{Acknowledgements}

The authors are grateful to CAPES - Coordination for the Improvement of Higher Education Personnel (Coordenação de Aperfeiçoamento de Pessoal de Nível Superior) and CNPq - The 
National Council for Scientific and Technological Development (Conselho Nacional de Desenvolvimento Científico e Tecnológico) for the financial support.

\section{References}

Abreu, F. R., Lima, D. G., Hamú, E. H., Wolf, C., \& Suarez, P. A. Z. (2004). Utilization of metal complexes as catalysts in the transesterification of Brazilian vegetable oils with different alcohols. Journal of Molecular Catalysis A Chemical, 209(1-2), 29-33. http:// dx.doi.org/10.1016/j.molcata.2003.08.003.

Allen, A. D., Anderson, W. A., Ayorinde, F. O., \& Eribo, B. E. (2010). Biosynthesis and characterization of copolymer poly(3HB-co-3HV) from saponified Jatropha curcas oil by Pseudomonas oleovorans. Journal of Industrial Microbiology \& Biotechnology, 37(8), 849-856. http://dx.doi.org/10.1007/s10295-010-0732-7. PMid:20467780

Aremu, M. O., Layokun, S. K., \& Solomon, B. O. (2010). Production of Poly(3-hydroxybutyrate) from cassava starch hydrolysate by Pseudomonas aeruginosa NCIB 950. Journal of Scientific and Industrial Research, 1(3), 421-426. http://dx.doi.org/10.5251/ ajsir.2010.1.3.421.426.

Ashby, R. D., Solaiman, D. K. Y., Foglia, T. A., \& Liu, C. K. (2001). Glucose/lipid mixed substrates as a means of controlling the properties of medium chain length poly(hydroxyalkanoates). Biomacromolecules, 2(1), 211-216. http://dx.doi.org/10.1021/ bm000098+. PMid:11749175

Association of Official Anaytical Chemists - AOAC. (1997). Official methods of analysis of the AOAC International. Gaithersburg: AOAC.

Bera, A., Dubey, S., Bhayani, K., Mondal, D., Mishra, S., \& Ghosh, P. K. (2015). Microbial synthesis of polyhydroxyalkanoate using seaweed-derivedcrude levulinic acid as co-nutrient. International Journal of Biological Macromolecules, 72, 487-494. http://dx.doi. org/10.1016/j.ijbiomac.2014.08.037.

Berezina, N., Yada, B., \& Lefebvre, R. (2014). From organic pollutants to bioplastics: insights into the bioremediation of aromatic compounds by Cupriavidus necator. New Biotechnology, 32(1), 47-53. http:// dx.doi.org/10.1016/j.nbt.2014.09.003. PMid:25252021

Borges, C. D., Moreira, A. N., Moreira, A. S., Del Pino, F. A. B., \& Vendruscolo, C. T. (2004). Characterization of biopolymers produced by Beijerinckia sp. 7070 at different culture times. Ciência e Tecnologia de Alimentos, 24(3), 327-332. http://dx.doi.org/10.1590/ S0101-20612004000300004.

Brandl, H., Gross, R. A., Lenz, R. W., \& Fuller, R. C. (1988). Pseudomonas Oleovorans as a source of poly(beta-hydroxyalkanoates) for potential applications as biodegradable polyesters. Applied and Environmental Microbiology, 54(8), 1977-1982. PMid:16347708.

Braunegg, G., Sonnleitner, B., \& Lafferty, R. M. (1978). A rapid gas chromatographic method for determination of poly-betahydroxybutiric acid in microbial biomass. Applied Microbiology and Biotechnology, 6(1), 29-37. http://dx.doi.org/10.1007/BF00500854.

Bugnicourt, E., Cinelli, P., Lazzeri, A., \& Alvarez, V. (2014). Polyhydroxyalkanoate (PHA): Review of synthesis, characteristics, processing and potential applications in packaging. Express Polymer Letters, 8(11), 791-808. http://dx.doi.org/10.3144/ expresspolymlett.2014.82.

Carvalho, L. J. C. B., Souza, C. R., Mattos Cascardo, J. C., Junior, C. B., \& Campos, L. (2004). Identification and characterization of a novel cassava (Manihot esculenta Crantz) clone with high free sugar content and novel starch. Plant Molecular Biology, 56(4), 643-659. http://dx.doi.org/10.1007/s11103-004-4873-9. PMid:15630625
Costa, S. G., Lépine, F., Milot, S., Déziel, E., Nitschke, M., \& Contiero, J. (2009). Cassava wastewater as a substrate for the simultaneous production of rhamnolipids and polyhydroxyalkanoates by Pseudomonas aeruginosa. Journal of Industrial Microbiology \& Biotechnology, 36(8), 1063-1072. http://dx.doi.org/10.1007/s10295009-0590-3. PMid:19471980

Darnet, S. H., Silva, L. H. M., Rodrigues, A. M. C., \& Lins, R. T. (2011). Nutritional composition, fatty acid and tocopherol contents of buriti (Mauritia flexuosa) and patawa (Oenocarpus bataua) fruit pulp from the Amazon region. Ciência e Tecnologia de Alimentos, 31(2), 488-491. http://dx.doi.org/10.1590/S0101-20612011000200032.

Davis, R., Kataria, R., Cerrone, F., Woods, T., Kenny, S., O’Donovan, A., Guzik, M., Shaikh, H., Duane, G., Gupta, V. K., Tuohy, M. G., Padamatti, R. B., Casey, E., \& O’Connor, K. E. (2013). Conversion of grass biomass into fermentable sugars and its utilization for medium chain length polyhydroxyalkanoate (mcl-PHA) production by Pseudomonas strains. Bioresource Technology, 150, 202-209. http://dx.doi.org/10.1016/j.biortech.2013.10.001. PMid:24177152

Diniz, S. C., Taciro, M. K., Gomez, J. G. C., \& Pradella, J. G. C. (2004). High-cell-density cultivation of Pseudomonas putida IPT 046 and medium-chain-length polyhydroxyalkanoate production from sugarcane carbohydrates. Applied Biochemistry and Biotechnology, 119(1), 51-70. http://dx.doi.org/10.1385/ ABAB:119:1:51. PMid:15496728

Du, G., \& Yu, J. (2002). Metabolic analysis on fatty acid utilization by Pseudomonas oleovorans: mcl-poly(3-hydroxyalkanoates) synthesis versus $\beta$-oxidation. Process Biochemistry, 38(3), 325-332. http:// dx.doi.org/10.1016/S0032-9592(02)00084-5.

Durner, R., Witholt, B., \& Egli, T. (2000). Accumulation of Poly[(R)3-hydroxyalkanoates] in Pseudomonas oleovorans during growth with octanoate in continuous culture at different dilution rates. Applied and Environmental Microbiology, 66(8), 3408-3414. http:// dx.doi.org/10.1128/AEM.66.8.3408-3414.2000. PMid:10919799

Escapa, I. F., García, J. L., Bühler, B., Blank, L. M., \& Prieto, M. A. (2012). The polyhydroxyalkanoate metabolism controls carbon and energy spillage in Pseudomonas putida. Environmental Microbiology, 14(4), 1049-1063. http://dx.doi.org/10.1111/j.1462-2920.2011.02684.x. PMid:22225632

Fiedler, S., Steinbüchel, A., \& Rehm, B. H. A. (2002). The role of the fatty acid $\beta$-oxidation multienzyme complex from Pseudomonas oleovorans in polyhydroxyalkanoate biosynthesis: molecular characterization of the fadBA operon from P. oleovorans and of the enoyl-CoA hydratase genes phaJ from P. oleovorans and Pseudomonas putida. Archives of Microbiology, 178(2), 149-160. http://dx.doi.org/10.1007/s00203-002-0444-0. PMid:12115060

Huijberts, G. N., Eggink, G., de Waard, P., Huisman, G. W., \& Witholt, B. (1992). Pseudomonas putida KT2442 cultivated on glucose accumulates poly(3-hydroxyalkanoates) consisting of saturated and unsaturated monomers. Applied and Environmental Microbiology, 58(2), 536-544. PMid:1610179.

Huisman, G. W., de Leeuw, O., Eggink, G., \& Witholt, B. (1989). Synthesis of poly-3-hydroxyalkanoates is a common feature of fluorescent pseudomonads. Applied and Environmental Microbiology, 55(8), 1949-1954. PMid:2506811.

Huisman, G. W., Wonink, E., De Koning, G. J. M., Preusting, H., \& Witholt, B. (1992). Synthesis of poly(3-hydroxyalkanoates) by mutant and recombinant Pseudomonas strains. Applied Microbiology and Biotechnology, 38(1), 1-5. http://dx.doi. org/10.1007/BF00169409.

Knoll, M., Hamm, T. M., Wagner, F., Martinez, V., \& Pleiss, J. (2009). The PHA Depolymerase Engineering Database: A systematic 
analysis tool for the diverse family of polyhydroxyalkanoate (PHA) depolymerases. BMC Bioinformatics, 10, 89. http://dx.doi. org/10.1186/1471-2105-10-89. PMid:19296857

Lithner, D., Larsson, A., \& Dave, G. (2011). Environmental and health hazard ranking and assessment of plastic polymers based on chemical composition. The Science of the Total Environment, 409(18), 3309-3324. http://dx.doi.org/10.1016/j.scitotenv.2011.04.038. PMid:21663944

Nitschke, M., \& Pastore, G. M. (2006). Production and properties of a surfactant obtained from Bacillus subtilis grown on cassava wastewater. Bioresource Technology, 97(2), 336-341. http://dx.doi. org/10.1016/j.biortech.2005.02.044. PMid:16171690

Olsen, K. M. (2004). SNPs, SSRs and inferences on cassava's origin. Plant Molecular Biology, 56(4), 517-526. http://dx.doi.org/10.1007/ s11103-004-5043-9. PMid:15630616

Pandey, A., Soccol, C. R., Nigam, P., Soccol, V. T., Vandenberghe, L. P. S., \& Mohan, R. (2000). Biotechnological potential of agro-industrial residues. II: cassava bagasse. Bioresource Technology, 74(1), 81-87. http://dx.doi.org/10.1016/S0960-8524(99)00143-1.

Praxedes, S. C., DaMatta, F. M., Loureiro, M. E., Ferrão, M. A. G., \& Cordeiro, A. T. (2006). Effects of long-term soil drought on photosynthesis and carbohydrate metabolism in mature robusta coffee (Coffea canefora Pierre var. kouillou) leaves. Environmental and Experimental Botany, 56(3), 263-273. http:// dx.doi.org/10.1016/j.envexpbot.2005.02.008.

Ramadas, N. V., Singh, S. K., Soccol, C. R., \& Pandey, A. (2009). Polyhydroxybutyrate Production using Agro-industrial Residue as Substrate by Bacillus sphaericus NCIM 5149. Brazilian Archives of Biology and Technology, 52(1), 1-23. http://dx.doi.org/10.1590/ S1516-89132009000100003.

Saharan, B. S., Grewal, A., \& Kumar, P. (2014). Biotechnological production of polyhydroxyalkanoates: A review on trends and latest developments. Chinese Journal of Biology, 2014, 1-18. http://dx.doi. org/10.1155/2014/802984.

Santhanam, A., \& Sasidharan, S. (2010). Microbial production of polyhydroxy alkanotes (PHA) from Alcaligens spp. and
Pseudomonas oleovorans using different carbon sources. African Journal of Biotechnology, 9(21), 3144-3150. http://dx.doi. org/10.5897/AJB10.018.

Shang, L., Jiang, M., Yun, Z., Yan, H. Q., \& Chang, H. N. (2008). Mass production of medium-chain-length poly(3-hydroxyalkanoates) from hydrolyzed corn oil by fed-batch culture of Pseudomonas putida. World Journal of Microbiology \& Biotechnology, 24(12), 2783-2787. http://dx.doi.org/10.1007/s11274-008-9808-1.

Smet, M. J., Eggink, G., Witholt, B., Kingma, J., \& Wynberg, H. (1983). Characterization of intracellular inclusions formed by Pseudomonas oleovorans during growth on octane. Journal of Bacteriology, 154(2), 870-878. PMid:6841319.

Srivastava, S. K., \& Tripathi, A. D. (2013). Effect of saturated and unsaturated fatty acid supplementation on bio-plastic production under submerged fermentation. Biotech, 3(5), 389-397. http:// dx.doi.org/10.1007/s13205-012-0110-4.

Steinbüchel, A. (2010). Microbiology monographs. In G. Q. Chen (Ed.), Plastics from bacteria: natural functions and applications (pp. 1862-5576). Berlin: Springer-Verlag.

Sudesh, K., Bhubalan, K., Chuah, J. A., Kek, Y. K., Kamilah, H., Sridewi, N., \& Lee, Y. F. (2011). Synthesis of polyhydroxyalkanoate from palm oil and some new applications. Applied Microbiology and Biotechnology, 89(5), 1373-1386. http://dx.doi.org/10.1007/s00253011-3098-5. PMid:21279347

Trinder, P. (1969). Determination of glucose in blood using glucose oxidase with an alternative oxygen acceptor. Annals of Clinical Biochemistry, 6(1), 24-27. http://dx.doi. org/10.1177/000456326900600108.

Urtuvia, V., Villegas, P., González, M., \& Seeger, M. (2014). Bacterial production of the biodegradable plastics polyhydroxyalkanoates. International Journal of Biological Macromolecules, 70(1), 208-213. http://dx.doi.org/10.1016/j.ijbiomac.2014.06.001. PMid:24974981

Vieira, E. A., Fialho, J. F., Faleiro, F. G., Bellon, G., Fonceca, K. G., \& Carvalho, L. J. C. B. (2011). Molecular characterization of sugary and non-sugary cassava accessions. Ciência e Agrotecnologia, 35(3), 455-461. http://dx.doi.org/10.1590/S1413-70542011000300003. 